\title{
Cell wall composition and lignin biosynthetic gene expression along a developmental gradient in an Australian sugarcane cultivar
}

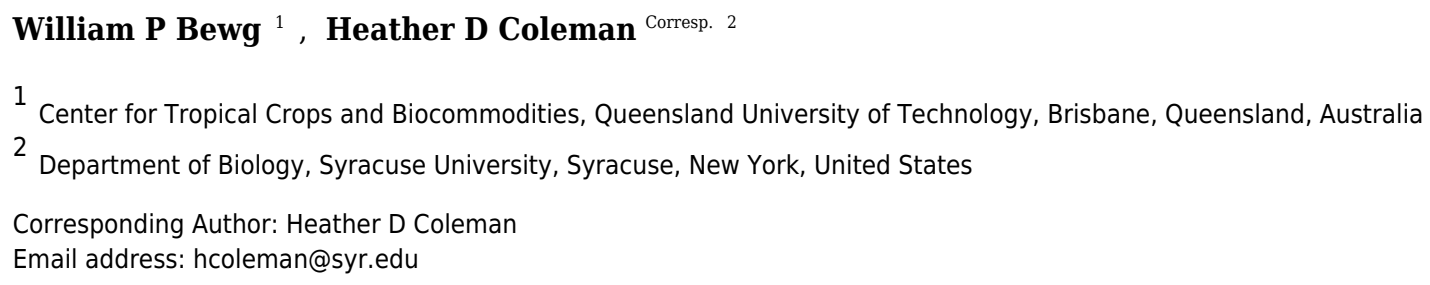

Sugarcane bagasse is an abundant source of lignocellulosic material for bioethanol production. Utilisation of bagasse for biofuel production would be environmentally and economically beneficial, but the recalcitrance of lignin continues to provide a challenge. Further understanding of lignin production in specific cultivars will provide a basis for modification of genomes for the production of phenotypes with improved processing characteristics. Here we evaluated the expression profile of lignin biosynthetic genes and the cell wall composition along a developmental gradient in KQ228 sugarcane. The expression levels of nine lignin biosynthesis genes were quantified in five stem sections of increasing maturity and in root tissue. Two distinct expression patterns were seen. The first saw highest gene expression in the youngest tissue, with expression decreasing as tissue matured. The second pattern saw little to no change in transcription levels across the developmental gradient. Cell wall compositional analysis of the stem sections showed total lignin content to be significantly higher in more mature tissue than in the youngest section assessed. There were no changes in structural carbohydrates across developmental sections. These gene expression and cell wall compositional patterns can be used, along with other work in grasses, to inform biotechnological approaches to crop improvement for lignocellulosic biofuel production. 
1 Cell wall composition and lignin biosynthetic gene expression along a

2 developmental gradient in an Australian sugarcane cultivar

3 Short title: Lignin biosynthesis profile in sugarcane

4 William P. Bewg ${ }^{1}$, Heather D. Coleman ${ }^{2 *}$

$5 \quad{ }^{1}$ Centre for Tropical Crops and Biocommodities, Queensland University of Technology

6 Brisbane, Queensland, Australia

$7 \quad{ }^{2}$ Department of Biology, Syracuse University, Syracuse, New York, United States of America

8 hcoleman@syr.edu

$9 *$ Corresponding author

10 Heather Coleman

11 Email: hcoleman@syr.edu 


\section{Abstract}

13 Sugarcane bagasse is an abundant source of lignocellulosic material for bioethanol production.

14 Utilisation of bagasse for biofuel production would be environmentally and economically

15 beneficial, but the recalcitrance of lignin continues to provide a challenge. Further understanding

16 of lignin production in specific cultivars will provide a basis for modification of genomes for the

17 production of phenotypes with improved processing characteristics. Here we evaluated the

18 expression profile of lignin biosynthetic genes and the cell wall composition along a

19 developmental gradient in KQ228 sugarcane. The expression levels of nine lignin biosynthesis

20 genes were quantified in five stem sections of increasing maturity and in root tissue. Two distinct

21 expression patterns were seen. The first saw highest gene expression in the youngest tissue, with

22 expression decreasing as tissue matured. The second pattern saw little to no change in

23 transcription levels across the developmental gradient. Cell wall compositional analysis of the

24 stem sections showed total lignin content to be significantly higher in more mature tissue than in

25 the youngest section assessed. There were no changes in structural carbohydrates across

26 developmental sections. These gene expression and cell wall compositional patterns can be used,

27 along with other work in grasses, to inform biotechnological approaches to crop improvement for

28 lignocellulosic biofuel production. 


\section{Introduction}

30 Sugarcane is a C4 perennial grass of high economic importance in many parts of the world

31 (Suprasanna et al. 2011). In addition to the production of high levels of sucrose in the stem, it

32 produces large amounts of lignocellulosic biomass that has the potential to be used for the

33 production of bioethanol (Canilha et al. 2012). Sugarcane is a particularly attractive source of

34 biomass for lignocellulosic biofuels production, as it is already transported to a central location

35 for the production of sugar. As a result, the bagasse remaining following sugar production is does

36 not require transport costs that otherwise represent a significant cost in bioethanol production.

37 However, as with all potential lignocellulosic feedstocks, the recalcitrance of the biomass

38 presents challenges that need to be addressed.

39 The deposition of the secondary cell wall is an important step in terrestrial plant development

40 (Weng \& Chapple 2010), involving the ordered deposition of cellulose and hemicellulose

41 followed by the impregnation of lignin polymers into this polysaccharide matrix (Vogel 2008).

42 Lignin polymers are comprised of guaiacyl $(\mathrm{G})$, syringyl $(\mathrm{S})$ and $p$-hydroxyl-phenyl $(\mathrm{H})$ units,

43 through oxidative polymerization of coniferyl, sinapyl and $p$-coumaryl alcohols respectively, that

44 are produced through the lignin biosynthesis pathway (Boerjan et al. 2003; Liu 2012).

45 Due to the importance of lignin in structural stability and water transportation, the role and

46 function of each gene within the lignin biosynthesis pathway is well established (Boerjan et al.

47 2003; Bonawitz \& Chapple 2010). The relationship between lignin and efficiency of

48 lignocellulosic bioethanol production has led to increased focus into lignin biosynthesis and

49 manipulation, and advances the possibility of cost-competitive bioethanol being produced from

50 lignin-altered sugarcane bagasse. Given the influence lignin has on cell wall digestibility, further 
51 understanding of control and timing of lignin deposition will be applicable for the genetic

52 modification of plants to specifically alter lignin characteristics.

53 While a number of studies have looked at cell wall formation in sugarcane previously (Bottcher

54 et al. 2013; de Souza et al. 2013; Lingle \& Thomson 2012), here we aim to assess the expression

55 profile of lignin biosynthetic genes and cell wall composition of a commercially relevant

56 Australian sugarcane cultivar (KQ228). In particular, we look at a developmental gradient to

57 further understand the relationship between gene expression and cell wall formation and

58 composition, with the goal of providing critical information for the biotechnological development

59 of improved varieties of sugarcane for second generation biofuel production.

60 Materials and methods

\section{Gene identification}

62 Primers were designed using sequences available from the NCBI database (Table 1). Not all

63 genes had annotated accessions available and consensus sequences were assembled from the

64 sugarcane EST database after BLAST analysis with the equivalent maize gene as a reference

65 sequence. The final consensus sugarcane sequences were created using only sugarcane EST

66 sequences. Amplicons of all lignin biosynthesis genes were run on a high-resolution gel to

67 confirm there was only one product, and then sequenced to determine primer specificity before

68 use in qRT-PCR.

\section{Plant material, growth conditions and tissue collection}

70 Sugarcane generated from callus (cultivar KQ228, generously provided by BSES Ltd, Meringa

71 Queensland) was acclimatized in growth chambers before being transferred to a greenhouse. 
72 KQ228 represents a commercially important smut-resistant cultivar in Queensland. Plants were

73 grown for nine months to the full height attainable in the greenhouse before being destructively

74 harvested for analysis. Each plant was divided into five different sections (A-E) to represent

75 increasing tissue maturity, with Section A being the youngest tissue and Section $\mathrm{E}$ being the most

76 mature tissue (Fig 1). Within each section, there were three nodes, and the topmost node was

77 used for qRT-PCR with the remaining two nodes used for cell wall composition.

78 Harvesting occurred between $10 \mathrm{am}$ and $2 \mathrm{pm}$ in a single session to minimize light or circadian

79 related fluctuations in gene expression levels (Rogers et al. 2005). For all stem analyses, only

80 internode tissue was used and node tissue was discarded. The root ball was washed to remove

81 potting mix and buttress roots (Moore 1987) were collected from each plant for qRT-PCR

82 analysis. Roots were included in the development of this profile to begin to gain a general

83 understanding of overall lignin biosynthetic gene expression in this tissue.

\section{RNA extraction and qRT-PCR}

85 RNA was extracted from all tissue samples using Tri Reagent (Sigma). Integrity of RNA was

confirmed by $2 \%$ agarose gel, and RNA concentrations quantified with a Nanodrop 2000

spectrophotometer. $1 \mu \mathrm{g}$ of RNA was treated with RQ1 RNase-free DNase (Promega). DNase-

treated RNA was used as a template for first strand cDNA synthesis using M-MLV Reverse

Transcriptase (Promega). RT negative samples were prepared by replacing reverse transcriptase

90 with water.

qRT-PCR was optimized to attain suitable $\mathrm{R}^{2}$ and PCR efficiency values, and primers were

validated against the housekeeping primers to ensure comparable rates of product amplification 
95 primers. Samples were prepared by a CAS1200 robot (Corbett) and analyzed using a Rotor-Gene

$96 \mathrm{Q}$ (Qiagen) Relative transcript levels were quantified using delta critical threshold values $(\Delta \mathrm{Ct})$

97 as previously described (Levy et al. 2004) using $\beta$-tubulin as the housekeeping gene (Rodrigues

98 et al. 2009).

\section{Cell wall composition}

100 Tissue for cell wall compositional analysis was prepared as previously described (Hames et al.

101 2008). Dried samples were milled to pass through a $2 \mathrm{~mm}$ screen and extracted overnight with

102 water and ethanol respectively (Sluiter et al. 2008c). A sample of this prepared material was dried

103 overnight at $105^{\circ} \mathrm{C}$ and used to determine the total solids (Sluiter et al. 2008a).

104 Cell wall composition was quantified by a modified acid hydrolysis method (Sluiter et al. 2008b)

105 using $0.125 \mathrm{~g}$ biomass, $1.5 \mathrm{~mL} 72 \%$ sulfuric acid and $42 \mathrm{~mL}$ of water. This acid hydrolysis method

106 was selected as it has been noted to provide an accurate assessment of lignin quantity (Jung et al.

107 1999). Samples were incubated at room temperature for two hours with regular mixing prior to

108 hydrolysis at $121^{\circ} \mathrm{C}$ for one hour. The hydrolysate was filtered through medium glass crucibles

109 and the acid insoluble lignin determined gravimetrically. Acid soluble lignin remaining in the

110 hydrolysate was determined by UV-Vis spectrophotometry. Cell wall carbohydrates, hydrolyzed

111 into their individual monomers, were analyzed using High Performance Liquid Chromatography.

112 A Waters e2695 Separations Module and Showa Denko Shodex SP-0810 sugar column $\left(85^{\circ} \mathrm{C}\right)$

113 with micro-guard de-ashing columns equipped with a Waters 2414 Refractive Index Detector

114 were employed.

115 Results

116 qRT-PCR expression profiles of lignin biosynthesis genes 
117 Expression profiles for the nine lignin biosynthesis genes were established after qRT-PCR 118 analysis of the five stem sections and the root tissue (Figs 1, 2 and 3, Fig S1). The $\Delta \mathrm{Ct}$ values

119 were normalized against Section A to allow for easier comparison of changes in expression in 120 relation to young tissue for each gene. The raw $\Delta \mathrm{Ct}$ values show that in Section $\mathrm{A}, \mathrm{PAL}$ is

121 expressed at levels greater than the other eight lignin biosynthesis genes analyzed (Table S1).

122 CCOAOMT, COMT and CCR also had greater expression levels in Section A than CAD, 4CL, $123 \mathrm{C} 4 \mathrm{H}, \mathrm{F} 5 \mathrm{H}$ and $\mathrm{C} 3 \mathrm{H}$. These trends are seen across the developmental gradient (Table S1).

124 The genes analyzed in stem tissue were separated into two general categories, those with highest 125 expression in Section A that decreased as stem tissue matured (PAL, CCR, 4CL, COMT and 126 CAD) (Fig 2), and those where expression showed little change across developmental stages 127 (C3H, F5H, C4H and CCoAOMT) (Fig 3). The expression pattern of the genes, and their 128 subsequent division into two groups, was not consistent with their position within the lignin 129 biosynthetic pathway (Fig S1).

Among the genes with highest expression in Section A (Fig 2), the difference between Section A 131 and the other sections is largest in PAL and CCR, with expression in Section B decreased by $70 \%$ $132-80 \%$ and by more than $90 \%$ in Section E. 4CL and COMT show a pronounced decrease in 133 expression, with only a 65\% decrease from Section A to Section B, with minor expression 134 decreases in older sections (Fig 2). CAD, the final gene in this group, showed the lowest expression difference among all five sections analyzed, with difference variation ranging from 25 to $40 \%$ (Fig 2). Only PAL and COMT show a significant reduction in expression in Section B when compared to Section A, but all five genes have significantly lower expression in Sections C, $138 \mathrm{D}$ and E relative to Section A. 
139 The second group shows similar expression across all five sections of stem tissue analyzed (Fig

140 3). $\mathrm{C} 4 \mathrm{H}, \mathrm{CCoAOMT}$ and $\mathrm{F} 5 \mathrm{H}$ all show no significant differences in expression levels across the 141 five stem sections. $\mathrm{C} 3 \mathrm{H}$ shows a significant increase in expression levels between Section A and 142 Section B before stabilizing in Sections C, D and E.

143 In root tissue, $\mathrm{C} 3 \mathrm{H}, \mathrm{CCoAOMT}, \mathrm{F} 5 \mathrm{H}$ and $\mathrm{CAD}$ expression was not significantly different to any 144 stem Section (A-E) (Figs 1, 2 and 3, Fig S1). Expression levels of PAL and 4CL were not 145 significantly different to Section A, but were significantly higher than Sections B-E (Fig 2). CCR 146 and COMT showed a similar pattern being not significantly different to Sections A or B but 147 significantly higher than expression in Sections C-E (Fig 2). Expression of C4H in root tissue 148 was approximately 9-fold higher than in any stem section (Fig 3).

\section{Cell wall compositional analysis}

150 Cell wall composition was quantified in the five stem sections (Table 2). Section A had

151 significantly lower lignin levels than the more mature stem internodes, though levels appear to 152 stabilize after Section B. This was due to lower acid insoluble lignin in Section A as there are no 153 significant differences in acid soluble lignin levels across the five stem sections. Glucose, xylose 154 and galactose did not vary across the developmental gradient, but arabinose levels were higher in 155 Section A than in more mature tissue. There was an inverse correlation between total lignin 156 content and arabinose content $\left(\mathrm{R}^{2}=0.89\right)$. This correlation was consistent with acid insoluble 157 lignin, but did not hold with acid soluble lignin.

\section{Discussion}

159 Sugarcane bagasse has great potential as a lignocellulosic biofuels source, in part, due to its 160 already being moved to a centralized location for sugar production. In order to effectively 
161 produce fermentable sugars from bagasse, the challenge of cell wall recalcitrance needs to be

162 overcome. Improved understanding of lignin biosynthesis and deposition in sugarcane will be of

163 great value when deciding the most appropriate approaches to facilitate the development of

164 commercial lines with increased saccharification potential. The work herein uses an economically

165 important smut-resistant Australian sugarcane cultivar, KQ228, and assesses lignin biosynthetic

166 gene expression and cell wall composition along a developmental gradient in an attempt to

167 further characterize the timing and location of lignin deposition to guide attempts to improve 168 bagasse for lignocellulosic biofuels production. It has been shown that disease resistance and

169 lignin content are often related (Cass et al. 2015; Yang et al. 2017), making this an attractive 170 cultivar for this work.

171 Whereas in our study we look only at one specific homologue for each lignin biosynthetic gene,

172 we have provided a comparison to previous work (Bottcher et al. 2013) wherein multiple

173 homologues are assessed (Table 1). Our work was based on available genome data at the time of

174 the study, and despite being somewhat limited relative to Bottcher et al. (2013), provides

175 confirmation and comparison with another economically important cultivar. In addition to this,

176 we also examined lignin gene expression in buttress roots as this can be a key storage sink for

177 carbon.

178 The trends in the stem expression data dichotomize the lignin biosynthesis genes. The two

179 'expression pattern groups' are genes for which expression decreases with tissue age (PAL, CCR,

$1804 \mathrm{CL}, \mathrm{COMT}$ and $\mathrm{CAD})$ or genes for which expression remains constant during maturation $(\mathrm{C} 3 \mathrm{H}$,

$181 \mathrm{~F} 5 \mathrm{H}, \mathrm{C} 4 \mathrm{H}$ and CCoAOMT). As PAL catalyzes the entry of metabolites into the lignin

182 biosynthesis pathway (Liu 2012; Weng \& Chapple 2010), its high level of expression in younger

183 tissue found in this study may represent an initial metabolic flux to provide a burst of metabolites

184 for the various phenylpropanoid pathways including lignin biosynthesis. CCR functions in the 
185 final stages of lignin biosynthesis and is considered a committed step, key in the production of

186 the individual lignin monomers (Vogt 2010; Weng \& Chapple 2010). Given the position of CCR

187 in the lignin biosynthesis pathway, it may act as a regulating control point for directing the

188 metabolic flux into lignin monomer production (Lacombe et al. 1997). As high expression of PAL

189 in young tissue may act to stimulate metabolic flux into phenylpropanoid production, high

190 expression of CCR in young tissue may ensure a high level of metabolite commitment into lignin

191 biosynthesis, which is fundamentally important for healthy plant development (Weng \& Chapple 192 2010).

193 The expression profiles of 4CL and COMT are similar to that of PAL and CCR, but they retain 194 slightly higher expression levels in more mature tissue. 4CL represents an important branch 195 where metabolites are directed either into lignin biosynthesis or to alternative phenylpropanoid 196 biosynthesis pathways (Vogt 2010; Weng \& Chapple 2010). Its position also allows for direct 197 metabolite contribution into $\mathrm{H}$ monomer biosynthesis or redirection of metabolites for $\mathrm{G}$ or $\mathrm{S}$ 198 monomer biosynthesis. The high level of 4CL expression in young tissue may reflect its response 199 to the metabolic flux into the phenylpropanoid pathway initiated by PAL. COMT is the last of 200 two enzymes entirely responsible for the production of the S lignin monomer within the lignin 201 biosynthesis pathway (Bonawitz \& Chapple 2010). The increased expression of COMT in young 202 tissue in this research may be to ensure S monomer production during the availability of the 203 initial metabolic flux. Previous work has shown that the RNAi suppression of COMT in 204 sugarcane resulted in decreased lignin and altered S:G ratio (Bewg et al. 2016).

205 The final gene showing a reduction in expression as stem tissue matures was CAD, though the 206 trend was not as strong as the previously discussed genes. CAD represents the final enzyme in the 207 lignin biosynthesis pathway catalyzing the production of precursor monolignols and committing 208 them to lignin monomer synthesis (Ferrer et al. 2008). The initial high expression of CAD in 
209 young tissue may relate to the increased metabolic flux through the lignin biosynthesis pathway.

210 Whereas overall trends between our work and previous research are the same for these genes with

211 decreasing expression for increasing maturity, there are differences, particularly with CAD and

212 COMT. The discrepancies between the current and published research may be a result of various

213 experimental differences between the current research and published findings, but it is more

214 likely that the differences arise from the differences in cultivars.

215 Three genes were identified with relatively consistent expression across the maturity gradient:

$216 \mathrm{C} 4 \mathrm{H}, \mathrm{F} 5 \mathrm{H}$, and CCoAOMT. Results for $\mathrm{C} 4 \mathrm{H}$ were consistent with other results (Papini-Terzi et

217 al. 2009). For F5H, expression in the Brazilian low and high lignin cultivars was highest in

218 intermediate aged internodes with the exception of the high lignin pith samples wherein it was

219 highest in the mature tissue (Bottcher et al. 2013). In the 30 cultivars with varying Brix levels,

220 F5H expression levels were higher in maturing stem tissue than in young tissue (Papini-Terzi et

221 al. 2009). Our results for CCoAOMT closely mirrored the results of Bottcher et al. (Bottcher et

222 al. 2013). We have previously published work describing the downregulation of both the F5H and

223 CCoAOMT in sugarcane, with the result being increased glucose release by enzymatic hydrolysis

224 but with no decrease in lignin. In the $\mathrm{F} 5 \mathrm{H}$ lines this was attributed to a change in the lignin

225 monomer ratio (Bewg et al. 2016)

226 The final gene assessed in our study, $\mathrm{C} 3 \mathrm{H}$, had the highest expression level in Section $\mathrm{B}$,

227 immediately below the most juvenile Section A. C3H catalyzes the second aromatic

228 hydroxylation reaction in the lignin biosynthesis pathway and is an important hub in controlling

229 metabolic flux into G and S lignin monomer synthesis (Barriere et al. 2004; Weng \& Chapple

230 2010). CCoAOMT, along with $\mathrm{C} 3 \mathrm{H}$, are hypothesized to be important control points for cell wall

231 lignification by acting as part of the ferulate production pathway (Barriere et al. 2004). Caffeoyl

232 CoA 3-O-methyltransferase is responsible for the 3' methylation of caffeoyl-CoA to produce 
233 feruloyl-CoA, a key step in the production of G and S lignin monomers (Hisano et al. 2009; Raes

234 et al. 2003). The feruloyl residues aid in cross-linking within the cell wall and may increase the

235 resistance of the cell wall to hydrolysis by adding to its structural stability (Barriere et al. 2004;

236 Bonawitz \& Chapple 2010; Grabber 2005). The relatively steady expression of CCoAOMT and

$237 \mathrm{C} 3 \mathrm{H}$ within the maturing sugarcane stem may reflect their continued requirement for feruloyl

238 residue production for ongoing cell wall lignification and not just their role in lignin monomer

239 biosynthesis.

240 Hydroxycinnamoyl transferase (HCT) was not included in qRT-PCR analysis as at the time of

241 this study a specific sequence could not be confidently identified. At that time, only one

242 published accession for sugarcane HCT was found (CA210265) (Casu et al. 2007). When

243 analyzed by BLAST it showed very close alignment with Zea mays anthranilate N-

244 benzoyltransferase (NM_001153992) (Soderlund et al. 2009). Further BLAST searching in the

245 sugarcane nucleotide and EST databases of NCBI with alternative HCT sequences from maize

246 (AY109546, DR807341) (Barrière et al. 2007) and from MAIZEWALL (2478084.2.1_REV,

247 2619423.2.1) (Guillaumie et al. 2007), Medicago sativa L. (AJ507825) (Shadle et al. 2007),

248 Nicotiana benthamiana (AJ555865) (Hoffmann et al. 2004), Coffea arabica (AM116757)

249 (Salmona et al. 2008) and Triticum aestivum L. (CK193498, CK199765) (Bi et al. 2011) did not

250 highlight any potential sugarcane HCT sequences, nor any conserved regions of sufficient length

251 to design primers (standard or degenerate) for potential use in sugarcane.

252 To our knowledge, this is the first paper that has looked at lignin biosynthetic gene expression in

253 sugarcane buttress roots. There were no significant differences in expression levels between root

254 tissue and the five stem sections (A-E) for C3H, CCoAOMT, F5H and CAD. Of these, C3H,

$255 \mathrm{CCoAOMT}$ and $\mathrm{F} 5 \mathrm{H}$ are all in the group with plateaued gene expression during development and

256 may highlight the promoters of these three genes as potential biotechnological tools to drive 
257 continuous and even expression of transgenes in sugarcane stem and root tissue. The only gene

258 with an unexpected level of expression was $\mathrm{C} 4 \mathrm{H}$ that had approximately 9-fold higher expression

259 in roots than in any stem section. This suggests that the $\mathrm{C} 4 \mathrm{H}$ promoter may be useful for

260 preferential expression of transgenes in sugarcane root tissue, however further analysis, including

261 the functionality of this promoter in additional tissue types, such as leaves, would need to be

262 assessed.

263 In addition to the assessment of lignin biosynthetic gene expression, we also examined the cell

264 wall composition along the same developmental gradient. It is well known that the composition

265 of the cell wall material changes as a plant matures due to secondary cell wall deposition.

266 Following cell elongation, the secondary cell wall is formed through the deposition of cellulose

267 and hemicellulose, followed by lignification (Vogel 2008; Weng \& Chapple 2010). Within

268 sugarcane, rapid elongation of young internode cells precedes cell wall thickening, including

269 lignification (Casu et al. 2007). No significant differences were seen in levels of structural

270 carbohydrates including glucose, xylose or galactose indicating that the deposition of structural

271 polysaccharides into the secondary cell wall had also occurred before harvesting of samples (in

272 more juvenile tissue). This is in contrast to published findings in sugarcane (Lingle \& Thomson

273 2012) and maize (Jung \& Casler 2006). In sugarcane, cellulose peaked and then declined below

274 internode 5, whereas hemicellulose was highest in young tissue before reducing to a steady state

275 (Lingle \& Thomson 2012). In maize, glucose content increased as tissue matured before

276 plateauing, and hemicellulose (xylose and arabinose) decreased as tissue matured before also

277 reaching a steady state (Jung \& Casler 2006). The decrease in xylose and arabinose coincided

278 with an increase in ferulates, and the authors suggest ferulates may be replacing the xylose and

279 arabinose within the cell wall, hence their decrease during tissue maturation (Jung \& Casler 280 2006). 
281 Results suggest the lignin deposition was complete by Section B as lignin content plateaued and

282 no differences were detected between Sections B, C, D and E. Other studies have also found that 283 overall lignin content increased with tissue maturity in wheat and maize (Jung \& Casler 2006; Ma 284 2007). In maize stem, lignin content decreased initially before increasing to a plateau (Jung \& 285 Casler 2006). In sugarcane, marked internodes harvested over a period of twelve weeks had 286 increased lignin content over time (Lingle \& Thomson 2012). In a second experiment, odd 287 numbered internodes harvested at a single time point, showed lignin content increased with 288 maturity, with the exception of a significant decrease in internode 3 (Lingle \& Thomson 2012).

289 The results of the second experiment are similar to the maize results of Jung and Casler (2006), 290 who suggest that young maize tissue is comprised of a higher percentage of lignified protoxylem 291 vessels than more mature tissue, that initially results in a high lignin content in very young tissue 292 (Jung \& Casler 2006). It is likely that the Section A tissue (from internodes 2 and 3) was in what 293 is the second zone identified in the studies by Jung and Casler (Jung \& Casler 2006) and Lingle 294 and Thomson (Lingle \& Thomson 2012). This is supported by the results of Bottcher et al. (2013) 295 who showed lower lignin levels in internode 2-4 of two sugarcane cultivars before reaching a 296 relatively steady state lignin level for internodes 5 to 18 . Only one paper has examined the lignin 297 content of root tissue, and the authors found only small changes in lignin content in the first $5 \mathrm{~cm}$ 298 of root development, with lignin levels ranging from 5-9\% (Leite et al. 2017).

299 Of note was the inverse relationship seen between lignin and arabinose content. This is likely the 300 result of the pattern of cell wall deposition, in which there is a natural progression from highly 301 substitute arabinoxylans to less branched xylan as cells fully expand. This natural progression 302 would also correspond with increasing lignin deposition (Carpita 1996; de O. Buanafina 2009). 303 This is consistent with previous results comparing cell wall properties across three Miscanthus 304 genotypes (De Souza et al. 2015). The work presented herein provides a profile of lignin 
305 biosynthetic gene expression and cell wall composition for an economically important Australian 306 sugarcane cultivar. The results support findings of previous groups and add additional

307 information on gene expression in sugarcane buttress roots. As a key potential biofuels crop,

308 detailed information from multiple cultivars will help to improve the understanding of lignin and

309 cell wall formation in this species and to inform biotechnological approaches to crop

310 improvement. 


\section{References}

312 Barriere Y, Ralph J, Mechin V, Guillaumie S, Grabber JH, Argillier O, Chabbert B, and Lapierre 313 C. 2004. Genetic and molecular basis of grass cell wall biosynthesis and degradability. II. Lessons from brown-midrib mutants. C R Biol 327:847-860. 10.1016/j.crvi.2004.05.010

Bewg WP, Poovaiah C, Lan W, Ralph J, and Coleman HD. 2016. RNAi downregulation of three key lignin genes in sugarcane improves glucose release without reduction in sugar production. Biotechnol Biofuels 9:270. 10.1186/s13068-016-0683-y

Bi CL, Chen F, Jackson L, Gill BS, and Li WL. 2011. Expression of lignin biosynthetic genes in wheat during development and upon infection by fungal pathogens. Plant Molecular Biology Reporter 29:149-161. 10.1007/s11105-010-0219-8

Boerjan W, Ralph J, and Baucher M. 2003. Lignin biosynthesis. Annu Rev Plant Biol 54:519-546. 10.1146/annurev.arplant.54.031902.134938

Bonawitz ND, and Chapple C. 2010. The genetics of lignin biosynthesis: connecting genotype to phenotype. Annu Rev Genet 44:337-363. 10.1146/annurev-genet-102209-163508

Bottcher A, Cesarino I, Santos AB, Vicentini R, Mayer JL, Vanholme R, Morreel K, Goeminne G, Moura JC, Nobile PM, Carmello-Guerreiro SM, Anjos IA, Creste S, Boerjan W, Landell MG, and Mazzafera P. 2013. Lignification in sugarcane: biochemical characterization, gene discovery, and expression analysis in two genotypes contrasting for lignin content. Plant Physiol 163:1539-1557. 10.1104/pp.113.225250

Canilha L, Kumar Chandel A, dos Santos Milessi TS, Fernandes Antunes FA, da Costa Freitas WL, das Gracas Almeida Felipe M, and da Silva SS. 2012. Bioconversion of sugarcane 
335

336

337

338

339

340

biomass into ethanol: an overview about composition, pretreatment methods, detoxification of hydrolysates, enzymatic saccharification, and ethanol fermentation. $J$ Biomed Biotechnol 2012:989572. 10.1155/2012/989572

Carpita NC. 1996. Structure and biogenesis of the cell walls of grasses. Annu Rev Plant Physiol Plant Mol Biol 47:445-476. 10.1146/annurev.arplant.47.1.445

Cass CL, Peraldi A, Dowd PF, Mottiar Y, Santoro N, Karlen SD, Bukhman YV, Foster CE, Thrower N, Bruno LC, Moskvin OV, Johnson ET, Willhoit ME, Phutane M, Ralph J, Mansfield SD, Nicholson P, and Sedbrook JC. 2015. Effects of PHENYLALANINE AMMONIA LYASE (PAL) knockdown on cell wall composition, biomass digestibility, and biotic and abiotic stress responses in Brachypodium. $J$ Exp Bot 66:4317-4335. 10.1093/jxb/erv269

Casu RE, Jarmey JM, Bonnett GD, and Manners JM. 2007. Identification of transcripts associated with cell wall metabolism and development in the stem of sugarcane by Affymetrix GeneChip Sugarcane Genome Array expression profiling. Funct Integr Genomics 7:153-167. 10.1007/s10142-006-0038-z

de O. Buanafina MM. 2009. Feruloylation in Grasses: Current and Future Perspectives. Mol Plant 2:861-872. https://doi.org/10.1093/mp/ssp067

De Souza AP, Kamei CLA, Torres AF, Pattathil S, Hahn MG, Trindade LM, and Buckeridge MS. 2015. How cell wall complexity influences saccharification efficiency in Miscanthus sinensis. $J$ Exp Bot 66:4351-4365. 10.1093/jxb/erv183

de Souza AP, Leite DCC, Pattathil S, Hahn MG, and Buckeridge MS. 2013. Composition and Structure of Sugarcane Cell Wall Polysaccharides: Implications for Second-Generation Bioethanol Production. BioEnergy Research 6:564-579. 10.1007/s12155-012-9268-1 
358 Ferrer JL, Austin MB, Stewart C, Jr., and Noel JP. 2008. Structure and function of enzymes involved in the biosynthesis of phenylpropanoids. Plant Physiol Biochem 46:356-370.

Grabber JH. 2005. How do lignin composition, structure, and cross-linking affect degradability?

Guillaumie S, San-Clemente H, Deswarte C, Martinez Y, Lapierre C, Murigneux A, Barriere Y, A review of cell wall model studies. Crop Science 45:820. 10.2135/cropsci2004.0191 expression profiling of cell wall biosynthesis and assembly in maize. Plant Physiol 143:339-363. 10.1104/pp.106.086405

Hames B, Ruiz R, Scarlata C, Sluiter A, Sluiter J, and Templeton D. 2008. Preparation of samples for compositional analysis: Laboratory analytical procedure (LAP). National Renewable Energy Laboratory Technical report: NREL/TP-510-42620.

Hisano H, Nandakumar R, and Wang Z-Y. 2009. Genetic modification of lignin biosynthesis for improved biofuel production. In Vitro Cellular \& Developmental Biology - Plant 45:306313. $10.1007 / \mathrm{s} 11627-009-9219-5$

Hoffmann L, Besseau S, Geoffroy P, Ritzenthaler C, Meyer D, Lapierre C, Pollet B, and Legrand M. 2004. Silencing of hydroxycinnamoyl-coenzyme A shikimate/quinate hydroxycinnamoyltransferase affects phenylpropanoid biosynthesis. Plant Cell 16:14461465. $10.1105 /$ tpc.020297

Jung HG, and Casler MD. 2006. Maize stem tissues: Cell wall concentration and composition during development. Crop Science 46:1793-1800.

Jung HJG, Varel VH, Weimer PJ, and Ralph J. 1999. Accuracy of Klason lignin and acid detergent lignin methods as assessed by bomb calorimetry. Journal of Agricultural and Food Chemistry 47:2005-2008. 
382 Lacombe E, Hawkins S, Van Doorsselaere J, Piquemal J, Goffner D, Poeydomenge O, Boudet

AM, and Grima-Pettenati J. 1997. Cinnamoyl CoA reductase, the first committed enzyme of the lignin branch biosynthetic pathway: cloning, expression and phylogenetic relationships. Plant J 11:429-441.

Leite DCC, Grandis A, Tavares EQP, Piovezani AR, Pattathil S, Avci U, Rossini A, Cambler A, De Souza AP, Hahn MG, and Buckeridge MS. 2017. Cell wall changes during the formation of aerenchyma in sugarcane roots. Annals of Botany:mcx050-mcx050. $10.1093 / \mathrm{aob} / \mathrm{mcx} 050$

Levy M, Edelbaum O, and Sela I. 2004. Tobacco mosaic virus regulates the expression of its own resistance gene N. Plant Physiol 135:2392-2397. 10.1104/pp.104.044859

Lingle SE, and Thomson JL. 2012. Sugarcane internode composition during crop development. BioEnergy Research 5:168-178. 10.1007/s12155-011-9153-3

Liu CJ. 2012. Deciphering the enigma of lignification: precursor transport, oxidation, and the topochemistry of lignin assembly. Mol Plant 5:304-317. 10.1093/mp/ssr121

Livak KJ, and Schmittgen TD. 2001. Analysis of relative gene expression data using real-time quantitative PCR and the 2(-Delta Delta C(T)) Method. Methods 25:402-408. 10.1006/meth.2001.1262

Ma QH. 2007. Characterization of a cinnamoyl-CoA reductase that is associated with stem development in wheat. $J$ Exp Bot 58:2011-2021. 10.1093/jxb/erm064

Moore PH. 1987. Anatomy and morphology. In: Heinz DJ, ed. Developments in crop science: Sugarcane improvement through breeding. Amsterdam: Elsevier, 85-142.

Papini-Terzi FS, Rocha FR, Vencio RZ, Felix JM, Branco DS, Waclawovsky AJ, Del Bem LE, Lembke CG, Costa MD, Nishiyama MY, Jr., Vicentini R, Vincentz MG, Ulian EC, Menossi M, and Souza GM. 2009. Sugarcane genes associated with sucrose content. BMC Genomics 10:120. 10.1186/1471-2164-10-120 
407 Raes J, Rohde A, Christensen JH, Van de Peer Y, and Boerjan W. 2003. Genome-wide 408 characterization of the lignification toolbox in Arabidopsis. Plant Physiol 133:1051-1071.

409

410 10.1104/pp.103.026484

Rodrigues FA, de Laia ML, and Zingaretti SM. 2009. Analysis of gene expression profiles under water stress in tolerant and sensitive sugarcane plants. Plant Science 176:286-302. 10.1016/j.plantsci.2008.11.007

Rogers LA, Dubos C, Cullis IF, Surman C, Poole M, Willment J, Mansfield SD, and Campbell MM. 2005. Light, the circadian clock, and sugar perception in the control of lignin biosynthesis. J Exp Bot 56:1651-1663. 10.1093/jxb/eri162

Salmona J, Dussert S, Descroix F, de Kochko A, Bertrand B, and Joet T. 2008. Deciphering transcriptional networks that govern Coffea arabica seed development using combined cDNA array and real-time RT-PCR approaches. Plant Mol Biol 66:105-124. $10.1007 /$ s 11103-007-9256-6

Shadle G, Chen F, Srinivasa Reddy MS, Jackson L, Nakashima J, and Dixon RA. 2007. Downregulation of hydroxycinnamoyl CoA: shikimate hydroxycinnamoyl transferase in transgenic alfalfa affects lignification, development and forage quality. Phytochemistry 68:1521-1529. 10.1016/j.phytochem.2007.03.022

Sluiter A, Hames B, Hyman D, Payne C, Ruiz R, Scarlata C, Sluiter J, Templeton D, and Wolfe J. 2008a. Determination of total solids in biomass and total dissolved solids in liquid process samples: Laboratory analytical procedure (LAP). National Renewable Energy Laboratory Technical report: NREL/TP-510-42621.

Sluiter A, Hames B, Ruiz R, Scarlata C, Sluiter J, Templeton D, and Crocker D. 2008b. Determination of structural carbohydrates and lignin in biomass: Laboratory analytical procedure (LAP). National Renewable Energy Laboratory Technical report: NREL/TP- 
432 Sluiter A, Ruiz R, Scarlata C, Sluiter J, and Templeton D. 2008c. Determination of extractives in

433 434 biomass: Laboratory analytical procedure (LAP). National Renewable Energy Laboratory Technical report: NREL/TP-510-42619.

Soderlund C, Descour A, Kudrna D, Bomhoff M, Boyd L, Currie J, Angelova A, Collura K, Wissotski M, Ashley E, Morrow D, Fernandes J, Walbot V, and Yu Y. 2009. Sequencing, mapping, and analysis of 27,455 maize full-length cDNAs. PLoS Genet 5:e1000740. 10.1371/journal.pgen.1000740

Suprasanna P, Patade VY, Desai NS, Devarumath RM, Kawar PG, Pagariya MC, Ganapathi A, Manickavasagam M, and Babu KH. 2011. Biotechnological developments in sugarcane improvement : An overview. Sugar Tech 13:322-335. 10.1007/s12355-011-0103-3

Vogel J. 2008. Unique aspects of the grass cell wall. Curr Opin Plant Biol 11:301-307. 10.1016/j.pbi.2008.03.002

Vogt T. 2010. Phenylpropanoid biosynthesis. Mol Plant 3:2-20. 10.1093/mp/ssp106

Weng JK, and Chapple C. 2010. The origin and evolution of lignin biosynthesis. New Phytol 187:273-285. 10.1111/j.1469-8137.2010.03327.x

Yang Q, He Y, Kabahuma M, Chaya T, Kelly A, Borrego E, Bian Y, El Kasmi F, Yang L, Teixeira P, Kolkman J, Nelson R, Kolomiets M, L Dangl J, Wisser R, Caplan J, Li X, Lauter N, and Balint-Kurti P. 2017. A gene encoding maize caffeoyl-CoA O-methyltransferase confers quantitative resistance to multiple pathogens. $49: 1364$. 10.1038/ng.3919 https://www.nature.com/articles/ng.3919\#supplementary-information 
Figure 1

Schematic of sampling sections along the sugarcane stem.

This schematic shows the sections that are discussed in all other figures and tables with Section $\mathrm{A}$ being the youngest tissue and Section $\mathrm{E}$ being the most mature tissue.

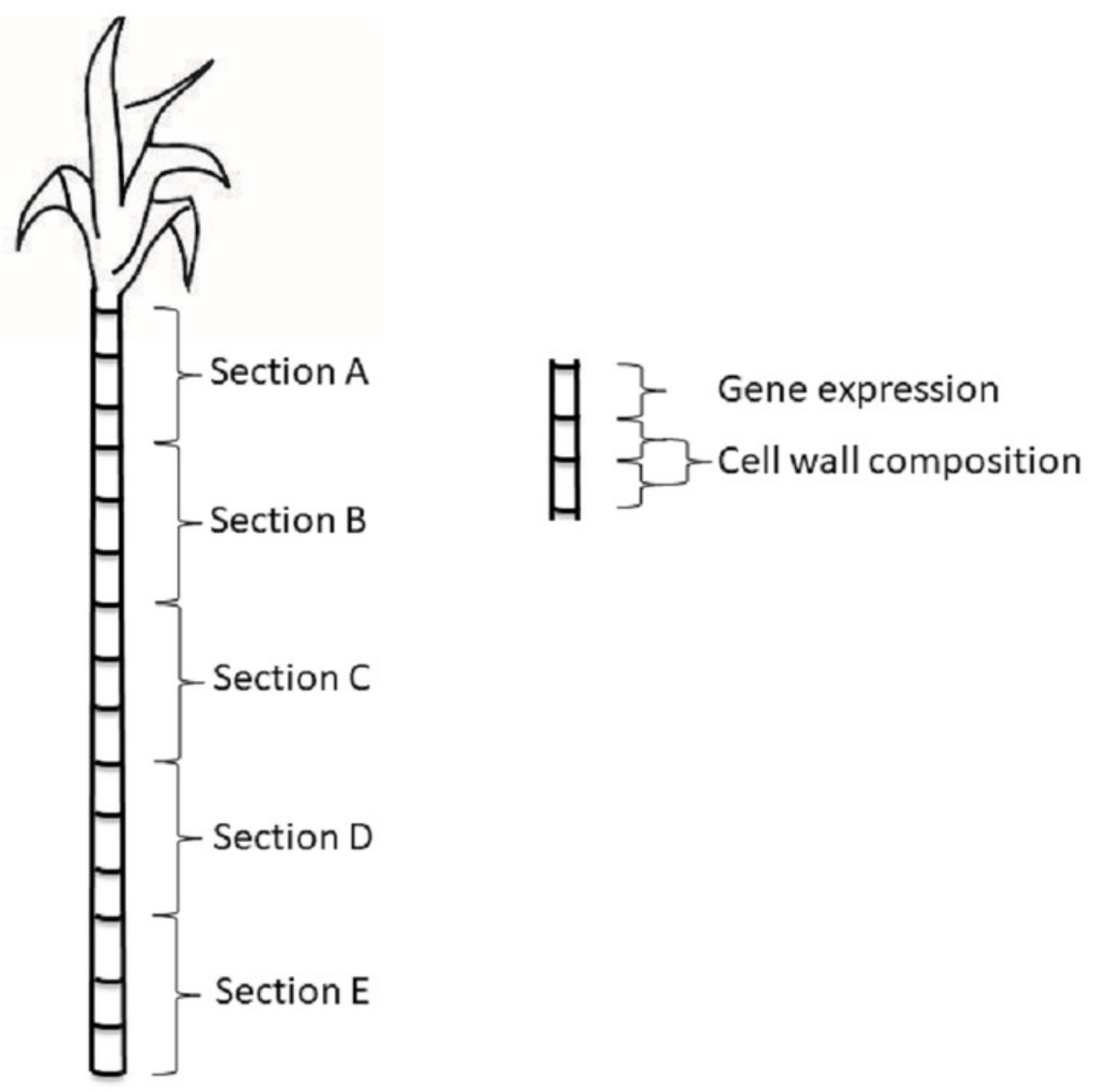




\section{Figure 2}

Genes with decreasing expression along developmental gradient

Genes showing highest expression in section A (young stem tissue) with decreased expression in more mature stem regions. $\Delta \mathrm{Ct}$ expression levels of lignin biosynthesis genes from the five stem sections and roots ( $n=5$ individual plants per tissue section) normalized against section $A$ for each individual gene is shown with standard error of the mean. Statistical differences are noted by different letters above bars $(x, y$ and $z)$ after ANOVA analysis with Tukey post-hoc analysis $(p=0.05)$. 

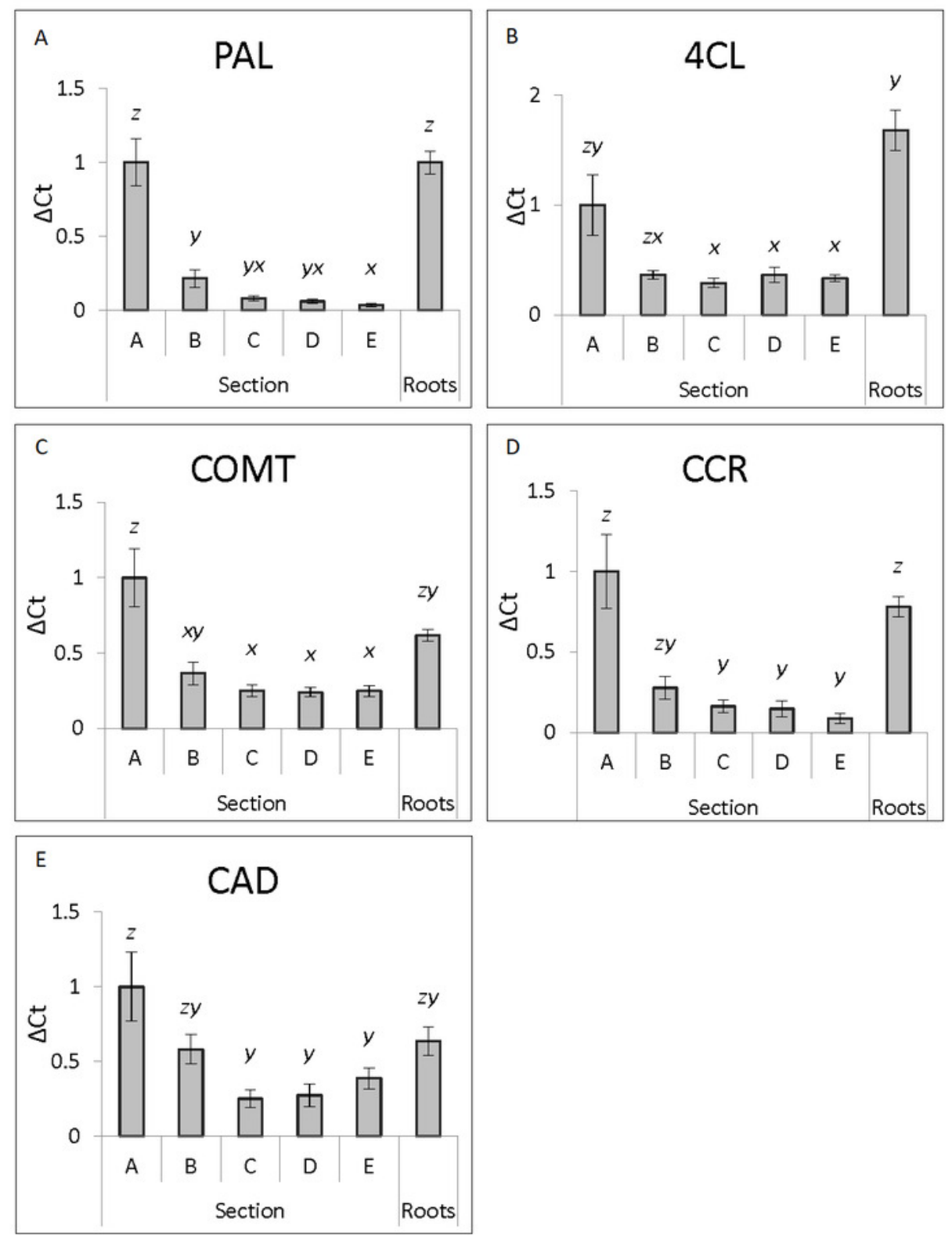


\section{Figure 3}

Genes showing consistent expression along developmental gradient

$\Delta C t$ expression levels of lignin biosynthesis genes from the five stem sections and roots $(\mathrm{n}=$ 5 individual plants per tissue section) normalized against section A for each individual gene is shown with standard error of the mean. Statistical differences are noted by different letters above bars $(x, y$ and $z)$ after ANOVA analysis with Tukey post-hoc analysis $(p=0.05)$. 

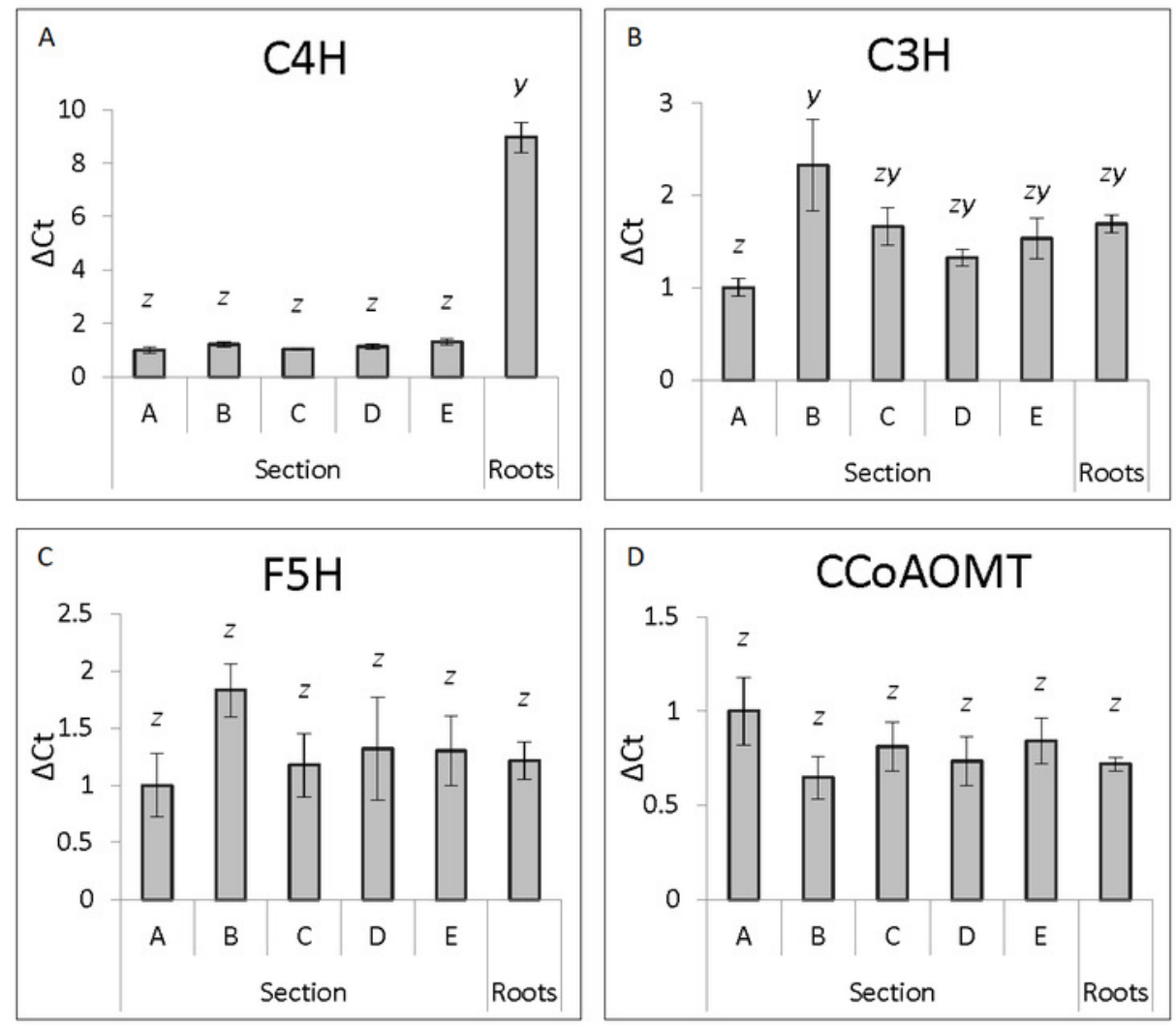


\section{Table $\mathbf{1}$ (on next page)}

qRT-PCR primers designed for the quantification of expression levels of lignin biosynthesis pathway genes 


\begin{tabular}{|c|c|c|c|c|c|c|}
\hline Amplicon & Forward (5'-3') & Reverse (5'-3') & $\begin{array}{l}\text { Size } \\
\text { (bp) }\end{array}$ & $\begin{array}{c}\text { Maize } \\
\text { Accession/ } \\
\text { EST numbers }\end{array}$ & $\begin{array}{l}\text { Sugarcane Accession/ } \\
\text { EST numbers }\end{array}$ & $\begin{array}{c}\text { Related } \\
\text { homologue } \\
\text { in Bottcher } \\
\text { et al. [25] }\end{array}$ \\
\hline$\beta$-Tubulin ${ }^{1}$ & GGAGGAGTACCCTGACAGAATGA $^{\mathrm{a}}$ & CAGTATCGGAAACCTTTGGTGAT & 68 & & $\mathrm{CA} 222437^{\mathrm{b}}$ & $\mathrm{N} / \mathrm{A}$ \\
\hline PAL & GACATCCTGAAGCTCATGTCG & ACCGACGTCTTGATGTTCTCC & 92 & & EF189195 & PAL1 \\
\hline $\mathrm{C} 4 \mathrm{H}$ & GTTCACCGTGTACGGCGACCACT & GAAGAAGGGCACCGTCATGATCC & 61 & AY104175 & $\begin{array}{c}\text { CA131376; CA146299; } \\
\text { CA196076; CA137884; } \\
\text { CA263105 }\end{array}$ & $\mathrm{C} 4 \mathrm{H} 1$ \\
\hline $4 \mathrm{CL}$ & CTTCCCGACATCGAGATCAACAAC & CTCATCTTCCCGAAGCAGTAGGC & 62 & $\begin{array}{l}\text { AY566301; } \\
\text { AX204868 }\end{array}$ & $\begin{array}{c}\text { CA184118; CA215779; } \\
\text { CA136560; CA176600; } \\
\text { CA135257 }\end{array}$ & $4 \mathrm{CL} 1$ \\
\hline $\mathrm{C} 3 \mathrm{H}$ & GTCGACGAGCAGGTCTTCAAAGC & CGTGCTCCTCCATGATCTTCAC & 73 & $\begin{array}{l}\text { AY107051; } \\
\text { BT086560 }\end{array}$ & CA262303; CA247763 & $\mathrm{C} 3 \mathrm{H} 2$ \\
\hline $\begin{array}{c}\text { CCoAOM } \\
\text { T }\end{array}$ & ACCTCATCGCAGACGAGAAGAAC & AGCCGCTCGTGGTAGTTGAGGTAG & 91 & $\begin{array}{c}\text { AJ242980; } \\
\text { EU952463; } \\
\text { NM_00115801 } \\
3\end{array}$ & $\begin{array}{c}\text { 5' end: CA168805; } \\
\text { CA071322; CA159865; } \\
\text { CA180815 } \\
\text { 3' end: CA159865; } \\
\text { CF575000; CA279207; } \\
\text { CA179873 }\end{array}$ & CCoAOMT1 \\
\hline $\mathrm{CCR}$ & AGCAGCCGTACAAGTTCTCG & GAAGGTTCTTCACCGTGTCG & 96 & & AJ231134 & No Match \\
\hline $\mathrm{F} 5 \mathrm{H}$ & GGTTCATCGACAAGATCATCGAC & GTCGGGGCTCTTCCCGCGCTTCAC & 53 & AX204869 & $\begin{array}{c}\text { 5' end: CA185931; } \\
\text { CA134666; CA135938 } \\
\text { 3' end: CA287472; } \\
\text { CA278023; CA253395; } \\
\text { CA103877 }\end{array}$ & F5H1 \\
\hline COMT & TACGGGATGACGGCGTTCGAGTAC & GTGATGATGACCGAGTGGTTCTT & 92 & & AY365419; AJ231133 & COMT1 \\
\hline $\mathrm{CAD}$ & ATCAGCTCGTCGTCCAAGAAG & ACCGTGTCGATGATGTAGTCC & 128 & & AJ231135 & CAD2 \\
\hline
\end{tabular}

${ }^{a}$ From Rodrigues et al. (2009) ${ }^{b}$ All EST sequences with the prefix ' $C A$ ' are from the Sugarcane Expressed Sequence Tag project (SUCEST) 


\section{Table 2 (on next page)}

Accumulation of individual cell wall components in stem regions of increasing maturity

The percentage of each component of the total composition is shown with the standard error of the mean. Values in bold type are significantly different (ANOVA analysis with Tukey posthoc analysis, $p=0.05$ ) to section A for each component. No significant differences were observed between sections $B, C, D$ or $E$ for any component. $n=5$. 
1

\begin{tabular}{ccccccccccccccc}
\hline \multirow{2}{*}{ Section } & \multicolumn{1}{c}{ Total lignin } & \multicolumn{2}{c}{$\begin{array}{c}\text { Acid } \\
\text { insoluble } \\
\text { lignin }\end{array}$} & \multicolumn{2}{c}{$\begin{array}{c}\text { Acid } \\
\text { soluble } \\
\text { lignin }\end{array}$} & \multicolumn{2}{c}{ Glucose } & \multicolumn{2}{c}{ Xylose } & \multicolumn{2}{c}{ Galactose } & \multicolumn{2}{c}{ Arabinose } \\
& $\%$ & $+/-$ & $\%$ & $+/-$ & $\%$ & $+/-$ & $\%$ & $+/-$ & $\%$ & $+/-$ & $\%$ & $+/-$ & $\%$ & $+/-$ \\
\hline A & 20.76 & 0.52 & 15.57 & 0.48 & 5.19 & 0.11 & 49.26 & 0.53 & 20.58 & 0.35 & 0.32 & 0.19 & 2.28 & 0.09 \\
B & $\mathbf{2 2 . 3 5}$ & $\mathbf{0 . 2 7}$ & $\mathbf{1 7 . 1 4}$ & $\mathbf{0 . 3 2}$ & 5.21 & 0.06 & 47.93 & 0.50 & 20.01 & 0.29 & 0.00 & 0.00 & $\mathbf{1 . 6 3}$ & $\mathbf{0 . 0 5}$ \\
C & $\mathbf{2 3 . 3 9}$ & $\mathbf{0 . 1 3}$ & $\mathbf{1 8 . 2 9}$ & $\mathbf{0 . 1 0}$ & 5.10 & 0.08 & 48.09 & 0.49 & 20.36 & 0.35 & 0.00 & 0.00 & $\mathbf{1 . 5 8}$ & $\mathbf{0 . 0 4}$ \\
D & $\mathbf{2 3 . 2 4}$ & $\mathbf{0 . 2 9}$ & $\mathbf{1 8 . 0 8}$ & $\mathbf{0 . 3 3}$ & 5.16 & 0.06 & 48.00 & 0.54 & 20.90 & 0.27 & 0.00 & 0.00 & $\mathbf{1 . 5 8}$ & $\mathbf{0 . 0 6}$ \\
E & $\mathbf{2 2 . 4 9}$ & $\mathbf{0 . 2 4}$ & $\mathbf{1 7 . 4 0}$ & $\mathbf{0 . 3 0}$ & 5.09 & 0.06 & 47.34 & 0.18 & 21.58 & 0.46 & 0.10 & 0.09 & $\mathbf{1 . 8 1}$ & $\mathbf{0 . 1 2}$ \\
\hline
\end{tabular}

2 